\title{
Detection of hail through the three-body scattering signatures and its effects on radar algorithms observed in Romania
}

\author{
DANIEL VICTOR CARBUNARU, MONICA SASU and SORIN BURCEA \\ National Meteorological Administration, Bucharest, Romania \\ Correponding author: D. V. Carbunaru; e-mail: daniel.carbunaru@meteoromania.ro \\ AURORA BELL \\ Bureau of Meteorology, Melbourne, Australia
}

Received October 10, 2012; accepted September 5, 2013

\begin{abstract}
RESUMEN
La red de radares de la Administración Meteorológica Nacional de Rumania (NMA, por sus siglas en inglés) integra cinco radares de la banda $\mathrm{S}$ y cuatro radares de la banda $\mathrm{C}$. La observación de procesos de convección en Rumania mediante la red de radares Doppler ofrece una nueva perspectiva para comprender el riesgo climatológico de ciertas regiones y entornos de mesoescala. Se observan mejor los sistemas convectivos altamente organizados, como las supercélulas, y su amenaza subsiguiente puede predecirse mejor durante el pronóstico a muy corto plazo (nowcasting) utilizando campos de velocidad Doppler y algoritmos de detección como mesociclones (MESO) y firmas de vórtice de tornados (TVS, por sus siglas en inglés). Sin embargo, para fines de prevención, estas herramientas no pueden utilizarse sin una validación subjetiva debido a los errores asociados y limitaciones de las observaciones de radar. En este trabajo se presentan varios casos en que la presencia de granizo de gran tamaño dentro de la tormenta produjo un artefacto de radar llamado "pico de granizo" (three-body scatter spike, TBSS) que alteró el campo de velocidad Doppler. Los casos presentados se observaron con radares de banda $\mathrm{S}$ y se compararon con informes de granizo sobre el terreno. El primer caso muestra un TBSS cuyas velocidades Doppler radiales son negativas debido a la presencia de hidrometeoros. El segundo exhibe una situación menos frecuente, cuando las velocidades Doppler en la región TBSS son positivas debido a la corriente ascendente. El tercer caso muestra valores positivos y negativos en la región TBSS; representa una supercélula con granizo de gran tamaño que afectó a la ciudad de Varna, en Bulgaria. Los valores positivos se asociaron con la región sobresaliente de la corriente rotacional ascendente a alturas superiores, en tanto que los valores negativos en las regiones externas de la corriente rotacional ascendente a alturas inferiores, se asociaron con las corrientes descendentes. Algunas anomalías producidas por el TBSS han alterado los resultados de los algoritmos TVS y MESO, introduciendo valores falsos de viento de gradiente fuerte que se han interpretado como rotación. De esta manera se generaron firmas falsas de mesociclones y vórtices de tornado. En algunos casos se reportaron tornados débiles y granizo de gran tamaño, por lo que la presencia de TBSS fue un reto para quienes realizan predicciones de muy corto plazo. En la parte final de este trabajo se analiza el vínculo entre la aparición de TBSS con informes de 2009 sobre granizo de gran tamaño en tierra en el área de cobertura de los radares de banda $\mathrm{S}$ en Rumania, que también abarcan zonas de Hungría, Bulgaria, Moldavia y Serbia. Los resultados muestran que la distorsión ocasionada por el TBSS es un fuerte indicador de granizo de gran tamaño.
\end{abstract}

\footnotetext{
ABSTRACT

The Romanian National Meteorological Administration (NMA) radar network consists of five S-band and four C-band radars. Observation of convection in Romania through the Doppler radar network offered a new perspective in understanding the climatologic risk of certain regions and mesoscale environments. Highly organized convective systems, such as supercells, are better observed and their subsequent threat can be better anticipated during the nowcasting process using Doppler velocity fields and detection algorithms
} 
such as mesocyclones (MESO) and tornadic vortex signature (TVS). However, for warning purposes, these tools cannot be used without a subjective validation because of the associated errors and limitations of radar observations. In this paper several cases are presented where the presence of large hail inside the storm produced a radar artifact named three-body scatter signature (TBSS) that disturbed the Doppler velocity field. The cases presented were observed with S-band radars and were associated with hail reports on the ground. The first case shows a TBSS whose radial Doppler velocities are negative due to the falling hydrometeors. The second case is a less frequent event; there the Doppler velocities in the TBSS region are positive due to the updraft. The third case has both positive and negative values in the TBSS region; it ocurred in a supercell that affected the city of Varna in Bulgaria with large hail. The positive values were associated with the overhang region in the rotational updraft at upper heights, while the negative values in the regions outside the rotational updraft at lower heights, were associated with the downdrafts. Features produced by the TBSS have perturbed the output of the MESO and TVS algorithms by introducing false strong values of wind shear that have been interpreted as rotation. Thus false mesocyclonic and tornadic vortex signatures were generated. In some of the cases large hail and weak tornadoes were reported, so the presence of a TBSS was a challenge for the nowcasters. In the last part of the paper we analyze the link between the TBSS appearance with reports of large hail at the ground in 2009 within the coverage area of the Romanian S-band radars, which also cover parts of Hungary, Bulgaria, the Republic of Moldova and Serbia. The results show that the TBSS artifact is a strong indicator of large-size hail.

Keywords: Three-body scatter signature, radial Doppler velocity field, hail, downdraft, updraft.

\section{Introduction}

In November 2000, the Romanian National Institute of Meteorology and Hydrology (INMH), today National Meteorological Administration (NMA), began to modernize its capabilities for detecting, monitoring and predicting meteorological and hydrological phenomena, by implementing the National Integrated Meteorological System - SIMIN project. SIMIN integrates five WSR-98D S-band radars with four existing C-band Doppler radars, to form a nine-unit Doppler radar network (Fig. 1). The WSR-98D is a clone version of the WSR-88D systems used in the US National Weather Service network. Currently, SIMIN produces individual site and national composite radar products every 6 minutes.

Advances in computer and radar technology, coupled with a dramatic increase in meteorological data sets, were not the only challenges to the forecasters. New conceptual models had to be learned and assimilated in operational practice as S-band radar allows the detection of severe weather associated with convective storms. Thus, mesocyclones (MESO), tornadic vortex signatures (TVS), low level and mid altitude convergence zones, became nolens volens usual terminology in nowcasting activities, despite a general belief that tornadic storms did not occur in Romania. Observing convection in Romania through the new S-band radar network provides a sharper perspective on mesoscale environments and the storms these environments create. Highly organized convective systems, such as supercells, can be better anticipated using useful radar pattern recognition software routines such as the MESO (Stumpf et al., 1998) and the TVS (Mitchell et al., 1998) algorithms. However, while these algorithms do demonstrate some skill they also are susceptible to radar artifacts and sampling limitations. Moreover, they sometimes fail to detect critical signatures that may be subtle or fail to meet certain thresholds. For this reason the meteorologist must carefully examine

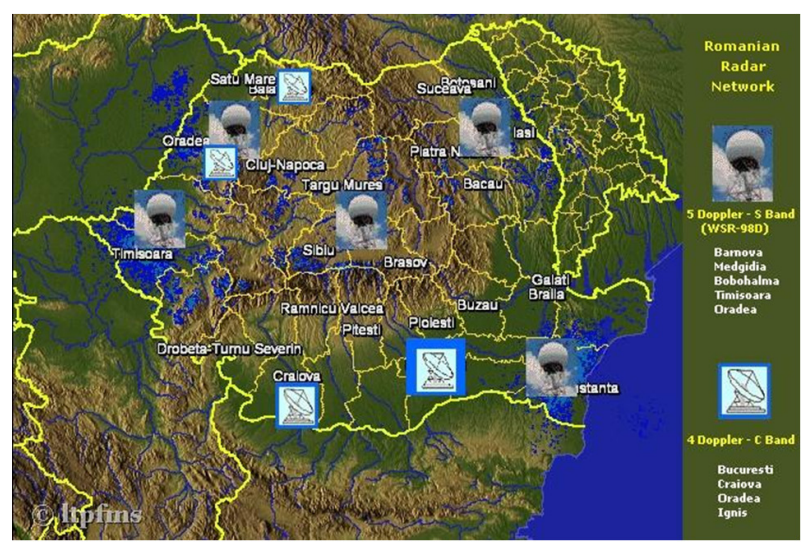

Fig 1. The SIMIN radar network: five WSR-98D S-band radars (an upgraded version of the WSR-88D radar used in the US NWS network) and four C-band radars (two from EEC -DWSR-2500C type and two from GematronikMETEOR 500C type). 
the base data, so as to evaluate potential signature existence or non-existence.

In some of the cases radar artifacts can contaminate the reflectivity and velocity structures. For example, the three-body scatter signature (TBSS) can be a challenge for the operational environment (Lemon, 1998; Lindley, 2007). The TBSS is a mid-level Doppler radar signature, generally a $10-30 \mathrm{~km}$ long region of artifact echo aligned radially downrange from a highly reflective ( $>60 \mathrm{dBZ})$ echo region. It is caused by non-Rayleigh radar microwave scattering or Mie scattering, as first explained by Zrnić (1987) and is widely used by operational forecasters as a sufficient but not necessary indication of very large hail within a severe thunderstorm (Carbunaru et al., 2010; Stan-Sion et al., 2007). Wilson and Reum (1988) also concluded that this radar echo artifact is the result of triple reflections, caused by non-Rayleigh radar microwaves scattering from a region of large hydrometeors, like wet hail. The triple reflections consist of: (1) a forward scattering by large hydrometeors to the ground below; (2) backscattering from the ground to the large hydrometeor region aloft, and (3) backscattering to the radar (Fig. 2). TBSS is also known as flare-echo (Wilson and Reum, 1988) or hail-spike (Zrnic, 1987). Lemon (1978, 1998) presented the TBSS and the operational application of this feature and described some aspects of WSR-88D detection and display of the signature, correlating the TBSS with other radar characteristics of hail producing

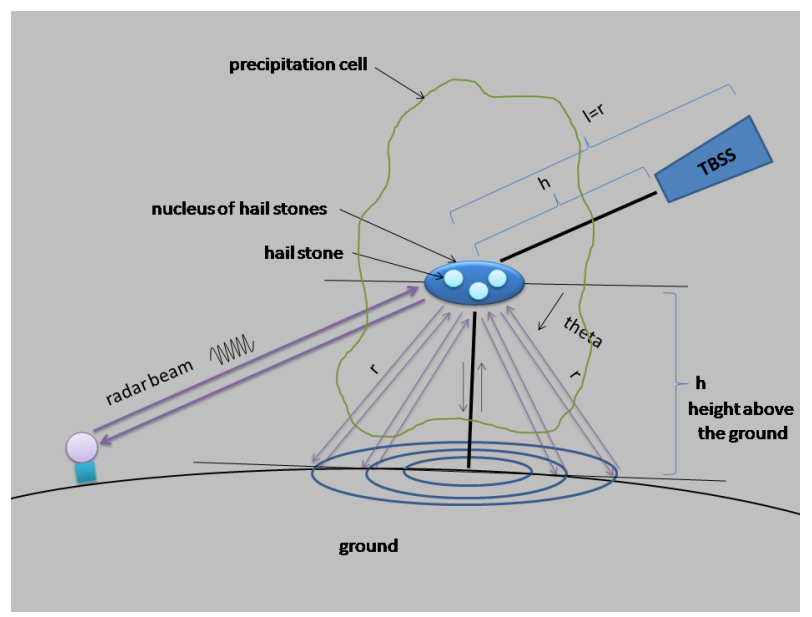

Fig. 2. Scheme of the radar signal path responsible for the three-body spike. The nucleus of the hailstone has reflectivities over the $60 \mathrm{dBz}$ core (adapted from Wilson and Reum, 1988). storms; he also mentioned that the TBSS can mask internal storm velocities. Combinations of TBSS and reflectivity may also be used to identify the size of the hail stones if the backscattering cross-section of the ground surface is known (Zrnic et al., 2010).

For warning purposes, the TBSS cannot give an anticipation of more than 30 minutes because the general life cycle of hail formation is of that order and it is easier detected at high levels in the storm where the geometry of the interactions produces a longer spike; however the hail spike can affect the radial velocities and can produce disruptions in the radial velocity field. These can generate unreal mesocyclonic and tornadic vortex patterns that can be artificially identified by the algorithm, due to unreal shears detected by the radar algorithms, and artificial labels can be produced (MESO, TVS). Also a true rotational field can be altered by the overlapping TBSS velocities. However, while these algorithms do demonstrate some skill they also are susceptible to radar artifacts and sampling limitations.

The paper is structured as follows: section 2 describes the operational aspects of the TBSS artifact, emphasizing the impact of the positive and negative Doppler velocities associated with the TBSS on radar data. The errors of the MESO algorithm produced by the presence of the TBSS are discussed in section 3. A short description of the spatial distribution of the TBSS observed with Romanian radar network is presented in section 4, followed by the conclusions.

\section{Operational aspects of the TBSS}

2.1 Negative Doppler velocities associated with TBSS While the structure of the TBSS in reflectivity is well known, the structure of the radial velocities in the spike region is less known and studied. In order to compute the vertical velocities associated with hydrometeors (hail stones), knowing the Doppler velocities in the storm and in the TBSS area respectively, Zrnic (1987) proposes the equation:

$v \approx v_{r}+w \sin \left(\theta_{r}\right)$

where $v$ are the velocities in the TBSS area, $w$ are the downdraft or updraft velocities associated with hydrometeors, $\theta_{r}$ is the theta angle in Figure 2 and $v_{r}$ are the velocities associated with the maximum radar reflectivity core of the storm. 
We can write Eq. (1) as:

$$
w \approx \frac{v-v_{r}}{\sin \left(\theta_{r}\right)}
$$

For the considered geometry, , because the TBSS has a finite length in the reflectivity and Doppler velocity fields (length on the scattering angle of electromagnetic radiation by hydrometeors), so that angle $\theta_{r}$ cannot be zero.

Next we used the bin notation for the radar resolution volume in the plan position indicator (PPI) reflectivity and Doppler velocity fields from the principal user processor (PUP) application. In these two-dimensional representations the radial resolution of the radar bin is about $1 \mathrm{~km}^{2}$ (along the radar beam), maintained at $1 \mathrm{~km}$ in both reflectivities and Doppler base velocities fields (http://www.wdtb.noaa.gov/ courses/dloc/index.html).

For the first bin inside the TBSS (bin 1 in Fig. 2 [the first white square]), angle $\theta_{r}$ is $\pi / 2$. Thus:

$\sin \left(\theta_{r}\right)=1$

from which

$w \approx v-v_{r}$

The next bins (next two or more white squares in Fig. 2) inside the TBSS area are subject to the next considerations:

- They were obtained considering the geometry of triangle ABC in Figure 2.

- The height above the ground $\mathrm{AB}=h$ inside the triangle is known from the WSR-98D radar algorithm.

- AC represents the distance between the considered maximum reflectivity core and the next radar bins in the TBSS area, which is equal to $h+k c$, $c$ being the distance between the middle of the radar bins in the TBSS area: $c=1 \mathrm{~km}$ and $k=$ $1,2,3,4, \ldots$ etc.

- Considering the tangent plane to the ground below the maximum reflectivity core, the triangle $\mathrm{ABC}$ is rectangular and the angle between $r(\mathrm{AC})$ and $h(\mathrm{AB})$ is $\left(\pi / 2-\theta_{r}\right)$.

Thus:

$\cos \left(\frac{\pi}{2}-\theta_{r}\right)=\sin \left(\theta_{r}\right)=\frac{h}{h+k c}$.
And for the secondary bins in the TBSS area:

$w \approx\left(v-v_{r}\right) \frac{h+k c}{h}$.

We used this formula to compute the vertical velocities for the studied cases because all variables are known from radar measurments. An example of the process through which negative velocities occur in the TBSS area when there is hailstone with negative velocities is rendered in Figure 3, where we consider an area (blue) with hail nuclei. Since those nuclei have negative (downdraft) speeds, the distance travelled by the pulse in two successive moments decreases. The Doppler processing assigns negative velocity to this change in the path length in the area where TBSS is initiated (green area in Fig. 3).

In our studies of Romanian cases we have observed that velocities in the spike region are most frequently negative. These vertical velocities are found in storms that produce large hail stones and have a high component downward that gives negative values in the spike region.

In order to exemplify the process described above we present a case study from June 19, 2006.

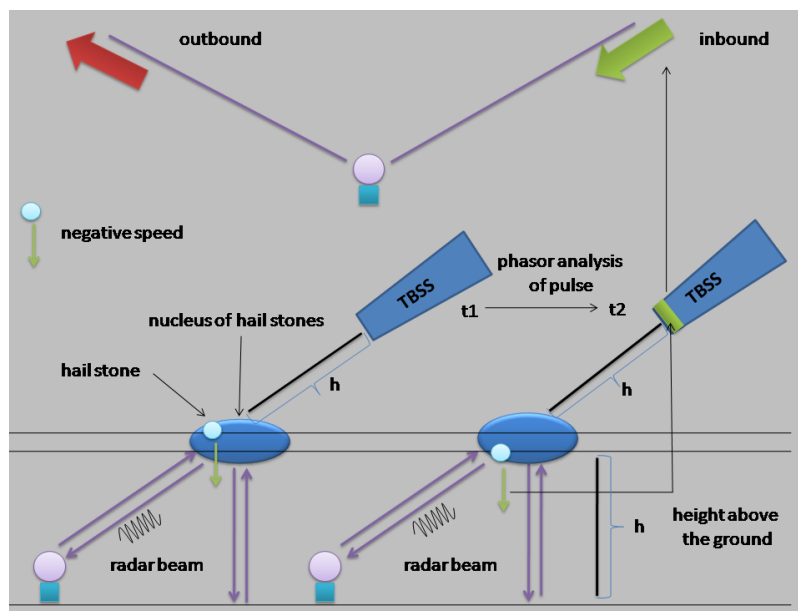

Fig. 3. Schematic representation of the physical and radar-analysis processes yielding negative speeds in the TBSS area.

\subsubsection{Case study - June 19, 2006}

The case presented was observed with the Iasi system (a WSR-98D S-band radar) on June 19, 2006, in the northeast part of Romania. This storm exhibited classic TBSS signatures. The Iasi radar was operating in volume coverage pattern (VCP) 21 with nine 

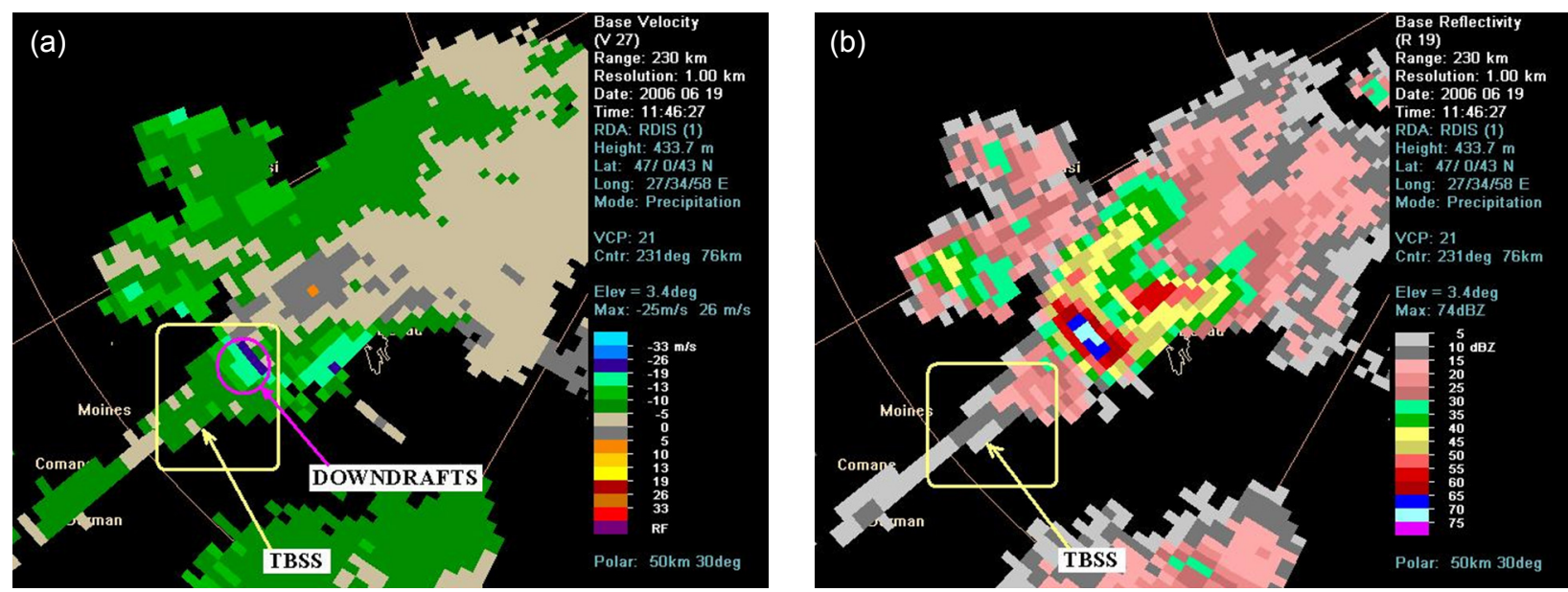

Fig. 4. TBSS (yellow rectangle) detected on June 19, 2006 at 1146 UTC by the WSR-98D Iasi radar at 2.4 . (a) Radial velocities field $\left(\mathrm{m} \mathrm{s}^{-1}\right)$; the purple circle compasses the region of strong downward velocities that produced a downdraft on the surface. (b) Reflectivity data in dBZ.

elevations scans every $6 \mathrm{~min}$. The first four elevations used in the operational environment were: $0.5^{\circ}, 1.5^{\circ}$, $2.4^{\circ}$ and $3.4^{\circ}$.

This case is indicative of the complexity that occurs in the Doppler radial speed field, when there is a rotation associated with the updraft of the storms, and the TBSS is also present (Fig. 4). The velocity field shows a sharp discontinuity behind the core of the cell (Fig. 5), in the TBSS region. The values are first positive and change into negatives in the spike (orange values). The hail on the ground was about $16 \mathrm{~mm}$ in diameter. It was recorded at Roman weather station (southeast of the storm in Fig. 5). The vertical

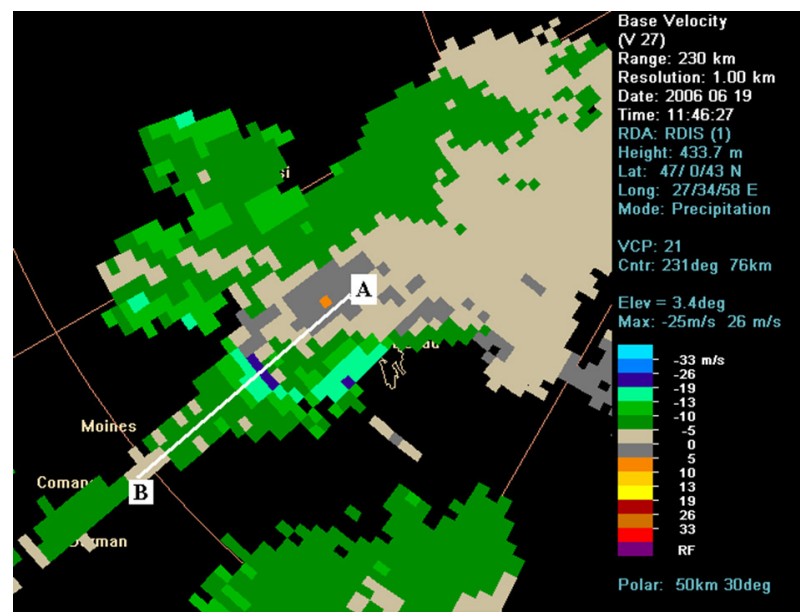

Fig. 5. Reflectivity data (dBZ) at 1146 UTC on June, 192006 at $2.4^{\circ}$. The AB line along the TBSS indicates the radial along which the values were analyzed and the distance along which the values for velocity were plotted. velocities computed in the TBSS area are shown in Figure 6. They are negative (from -5 to $-20 \mathrm{~m} \mathrm{~s}^{-1}$ ), being associatnes with negative speeds reside there is presented in Figure 7, which shows that the distance travelled by the ed with the downdraft flows.

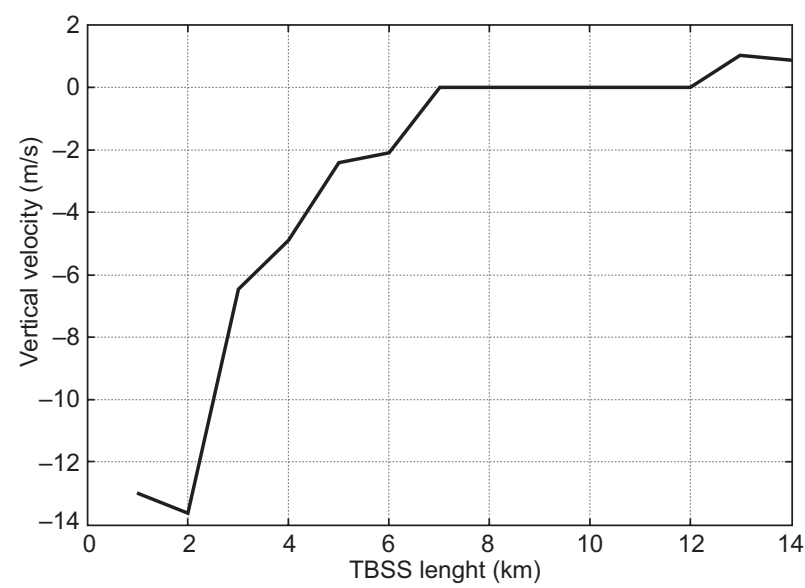

Fig. 6. Vertical velocities computed with Eq. (1) for the June 19, 2006 case at 1354 UTC.

\subsection{Positive Doppler velocities associated with the TBSS}

For the positive velocities in the TBSS area, which are much rarer in the analyzed cases, the same relationship (1) is used as in the case of the negative velocity. These positive velocities are associated with strong updraft speeds, able to keep large suspended hail stones $(5-10 \mathrm{~cm}$ in size). The process through which positive speeds occur in the TBSS area when hail storadar pulse at two successive moments because 


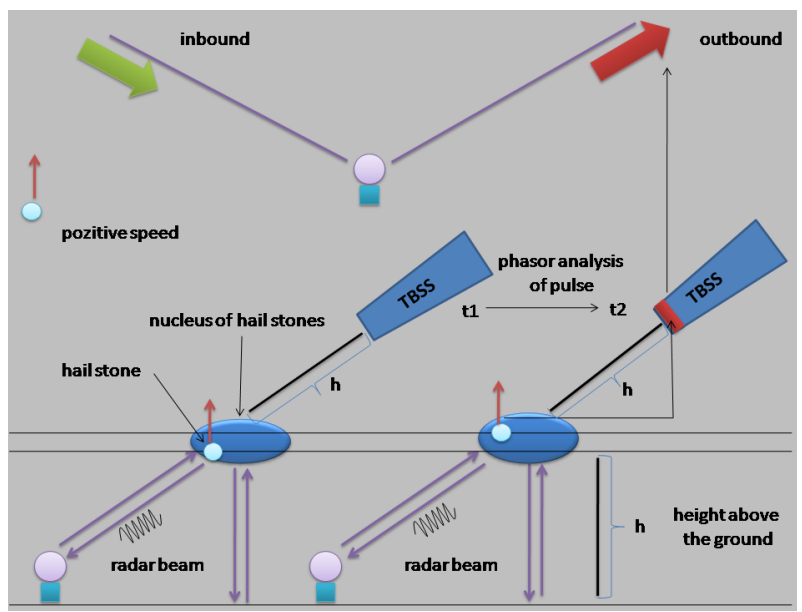

Fig. 7. Schematic display of the physical and radar analysis processes through which positive speeds in the TBSS area are obtained.

of the positive velocities of the hail stones, yields positive values in the area where the TBSS occurs (area marked with red in Fig. 7).

\subsubsection{Case study - 20 May 2006}

In this case the storm produced hail stones with diameters of about $7 \mathrm{~cm}$ at Negresti, a village in Moldavia. The TBSS (Fig. 8) contaminates the base velocity field with positive velocities due to the presence of a strong updraft at lower level. This updraft promoted the growth of very large hail, and the growing hailstones were carried across the updraft by the conserved, low-level, horizontal momentum feeding the updraft from below. For this reason the Doppler unit detected horizontal positive velocities in the hail region with a component of the low-level storm inflow.

The radial Doppler speeds and reflectivity presented in Figure 8a, b are taken along the $\mathrm{AB}$ section in Figure 9. The section starts from the center of maximum reflectivity, on the radar radius (exactly opposite to the radar), to the last $5 \mathrm{dBZ}$ reflectivity. Unlike the previous case, here the Doppler velocities associated with the TBSS are positive, which indicates the presence of updraft in the region of strong reflectivity of the overhang. The vertical velocities have values of 10 to $20 \mathrm{~m} \mathrm{~s}^{-1}$ (Fig. 10).

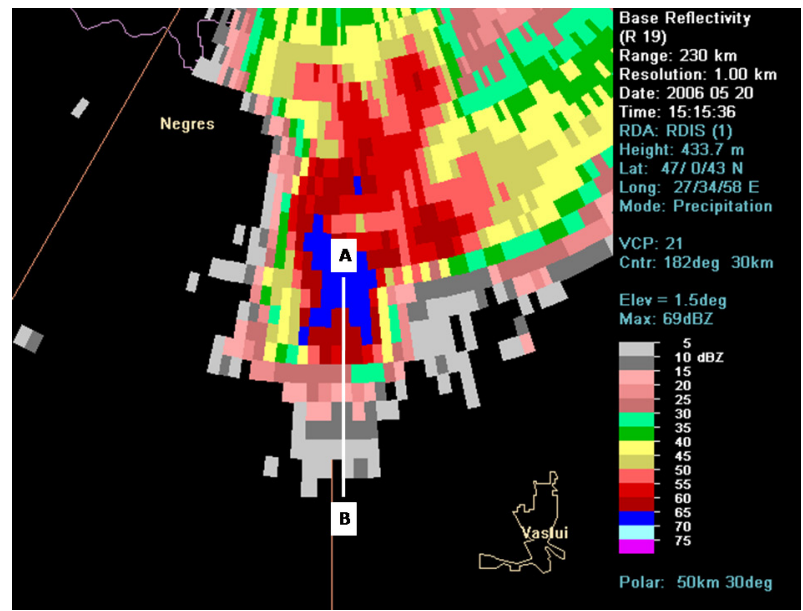

Fig. 9. Reflectivity data (dBZ) at 1515 UTC on May 20, 2006 at $1.5^{\circ}$. The AB line along the TBSS indicates the radial along which the values were analyzed and the distance along which the values for velocity were plotted.
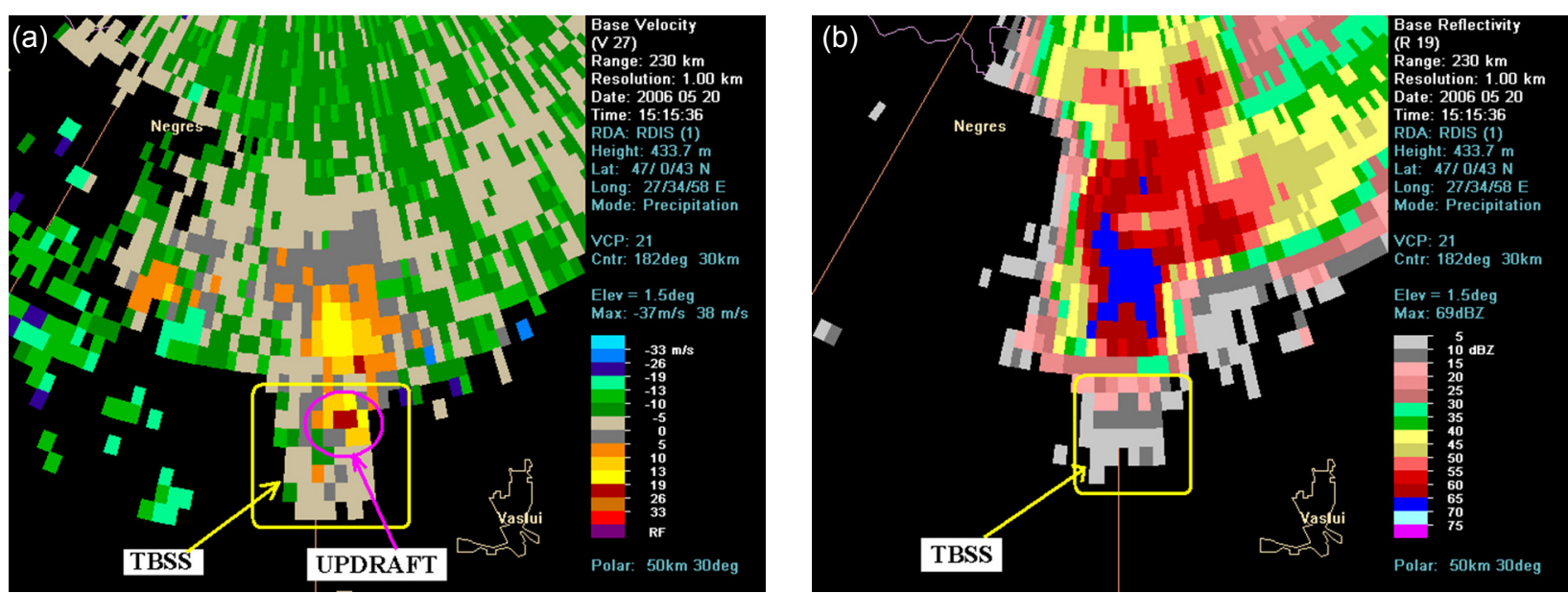

Fig. 8. TBSS detected on May 20, 2006 at 1515 UTC on the WSR-98D Iasi radar at $1.5^{\circ}$. (a) Radial velocities field $\left(\mathrm{m} \mathrm{s}^{-1}\right)$; the purple circle compasses the region where the base velocity field is contaminated with positive velocities associated with the TBSS, indicated by the yellow rectangle. (b) Reflectivity data in dBZ. 


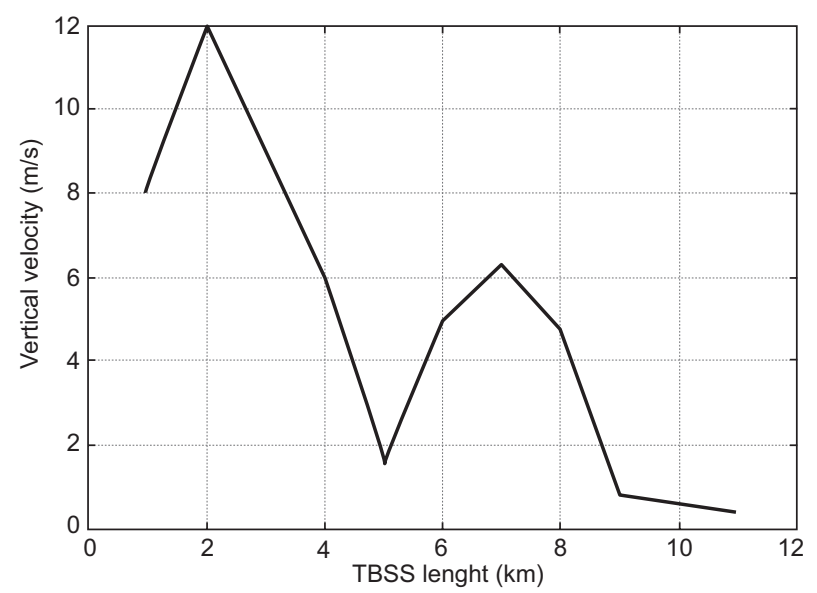

Fig. 10. Vertical velocities computed with Eq. (1) for the May 20, 2006 case at 1515 UTC.

\subsection{Positive and negative Doppler velocities asso-} ciated with the TBSS during the same storm

On September 27, 2004 the S-band radar installed at Medgidia, Romania detected a very strong storm
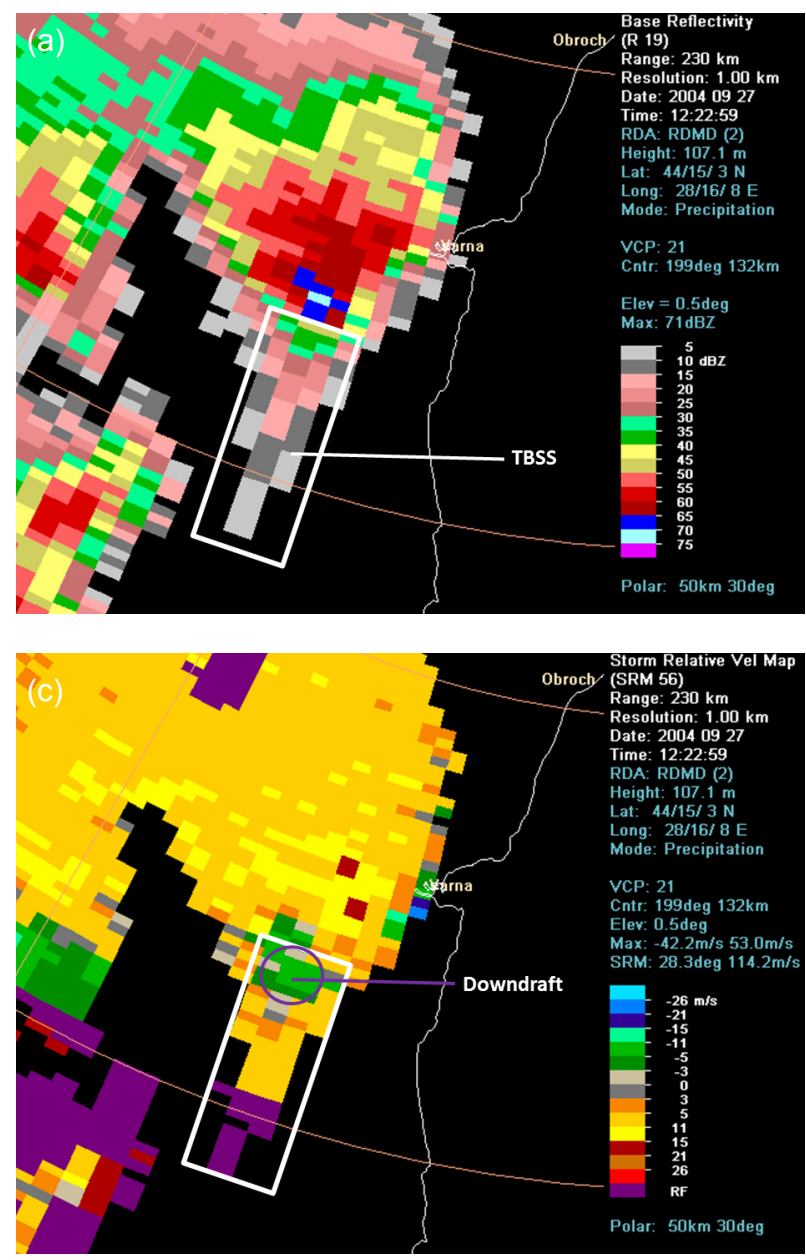

in the city of Varna, Bulgaria. According to the European Severe Weather Data Base (ESWDB) the storm produced $4 \mathrm{~cm}$ hailstones and two victims in 15 minutes. According to the radar data, at 1222 UTC the storm was situated southwest of the city, and a TBSS could be observed both on the base reflectivity and Doppler velocity fields at the first tilt (Fig.11). The TBSS region displays negative velocities associated with the downdraft region close to the high reflectivity core of 60-70 dBZ, west of the city of Varna. On the storm relative velocities we can observe a rotational structure close to the city of Varna (Fig. 11c), and we notice the presence of negative relative velocities in the TBSS region.

The upper tilt $\left(1.5^{\circ}\right)$ in the reflectivity field displays an extended intensive core of 65-70 dBZ. This nucleus is situated closer to the city and eastward and upward of the previous one (Fig. 12a). In the base field (Fig. 12b) we observe negative values in the region of the TBSS. The upper negative velocities

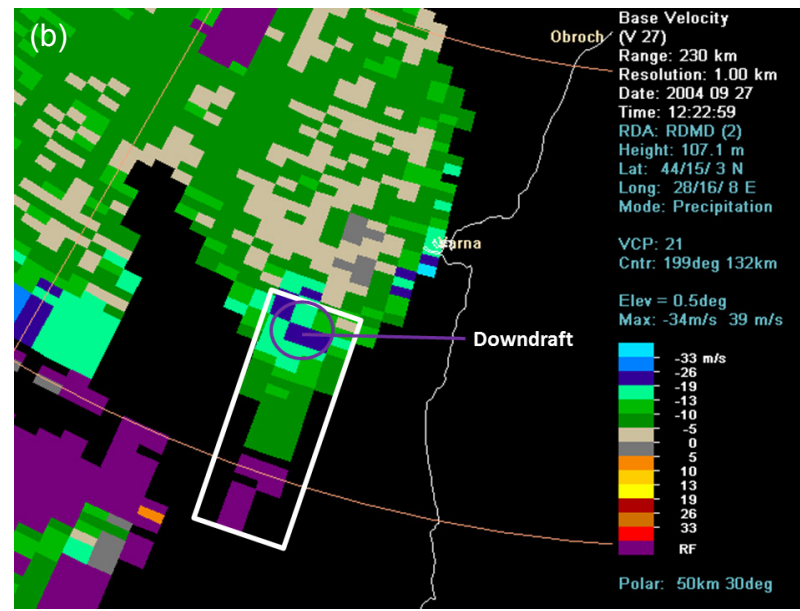

Fig. 11. Base reflectivity (a), base velocity (b) and relative velocity (c) at $0.5^{\circ}$ and 1222 UTC for June 27, 2004 from the WSR-98D radar at Medgidia. The white rectangle indicates the position of the TBSS. 

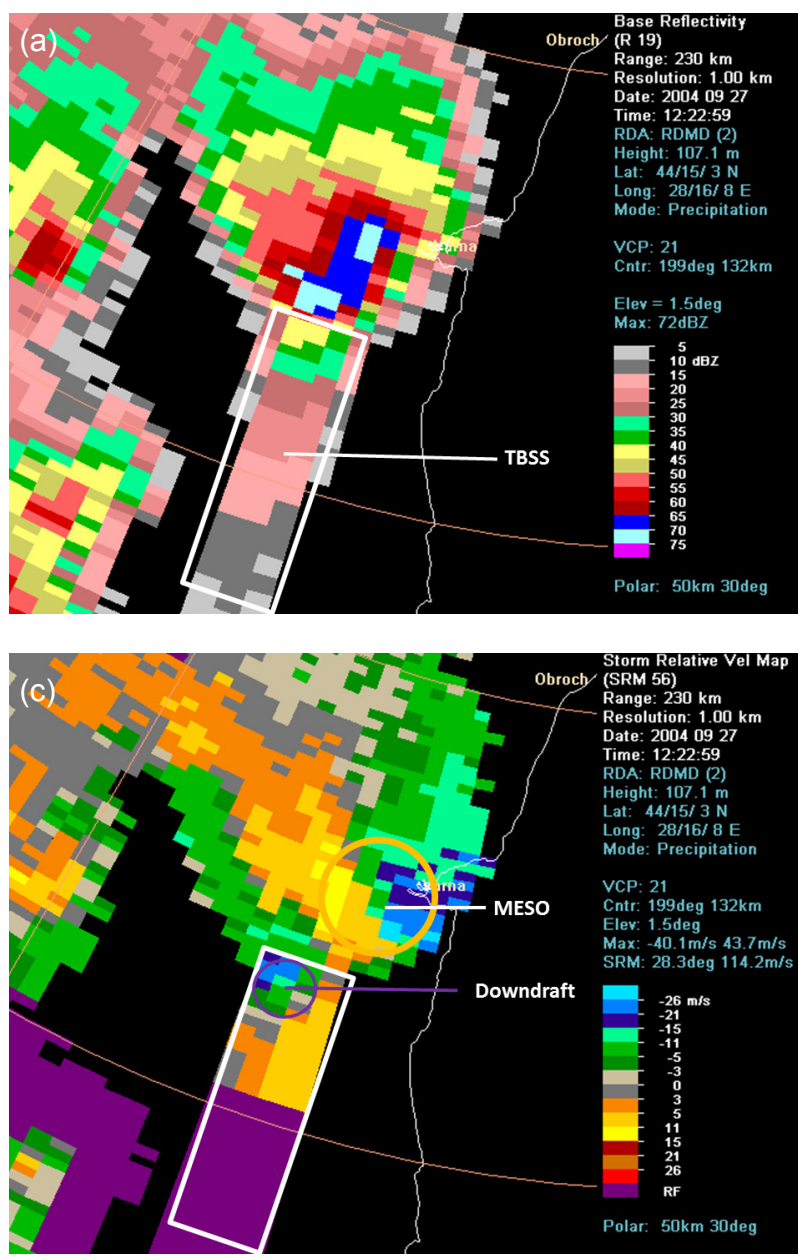

maxima overlap the lower maxima. In the region of the TBSS, negative velocities at the $1.5^{\circ}$ tilt are displaced to the left (in the downdraft region). At this height we can notice the cyclonic rotation close to the city of Varna, negative velocities just over the city, and zero velocities to the west of the city. The rotational structure becomes clearer in the storm relative field at the $1.5^{\circ}$ tilt (Fig. 12c, the yellow circle indicates the cyclonic region). Negative velocities in the region of the TBSS can be observed much better and are more representative in the relative field too. The downdraft region is also correlated with a region of convergence in the relative field, exactly in the region of the maximum reflectivity (Fig. 12a, c). At the $2.4^{\circ}$ tilt in upper levels, the nucleus of maximum reflectivity of $70-75 \mathrm{dBZ}$ is placed closer to Varna and to the east of the maximum reflectivity from lower tilts (Fig. 13a). The base velocities field is similar to the one at a lower tilt and displays the rotational structure and region of the downdraft (Fig. 13b) as-

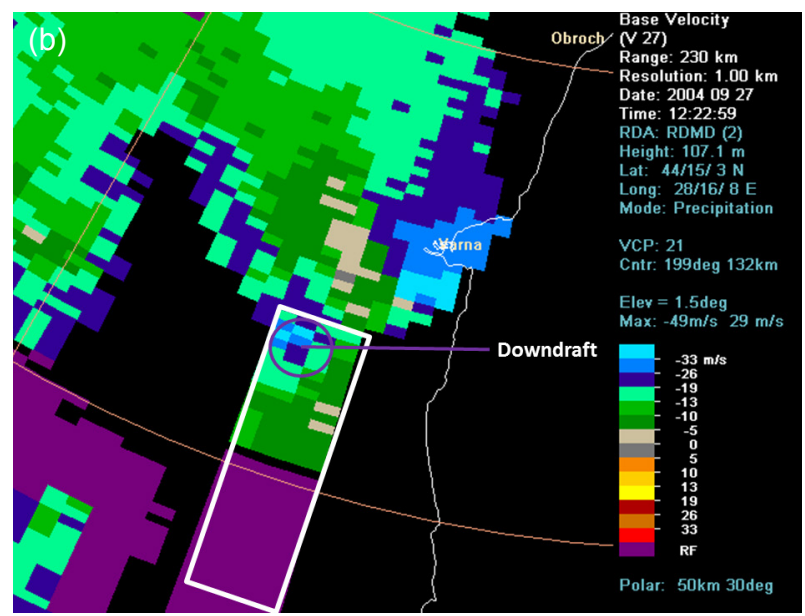

Fig. 12. Base reflectivity (a), base velocity (b) and relative velocity (c) at $1.5^{\circ}$ and 1222 UTC for June 27, 2004 from the WSR-98D radar at Medgidia. The white rectangle indicates the position of the TBSS.

sociated with the TBSS region. We also noticed the positive velocities in the TBSS region (Fig. 13b, c) that can be produced by the hydrometeors from the upper part of the updraft, which is collocated with the rotational structure.

We conclude that in the area of the TBSS there are also positive velocities because at the $0.5^{\circ}$ and $2.4^{\circ}$ tilts, in the Doppler velocities field on the right side of the TBSS, the negative values decrease and the positive values in the relative velocities field increase and expand.

The overhang region of the supercell is observed at the $3.4^{\circ}$ tilt, where the maximum reflectivity is positioned over the city of Varna and aligned on the same vertical axis with the mesocylone (Fig. 14a). The base velocities in the region of the TBSS (Fig. 14b) display values around zero in the updraft region, while the relative velocities field (Fig. 14c) displays positive values in the updraft region. At 1222 UTC, just before reaching Varna city, the mesocylone had 

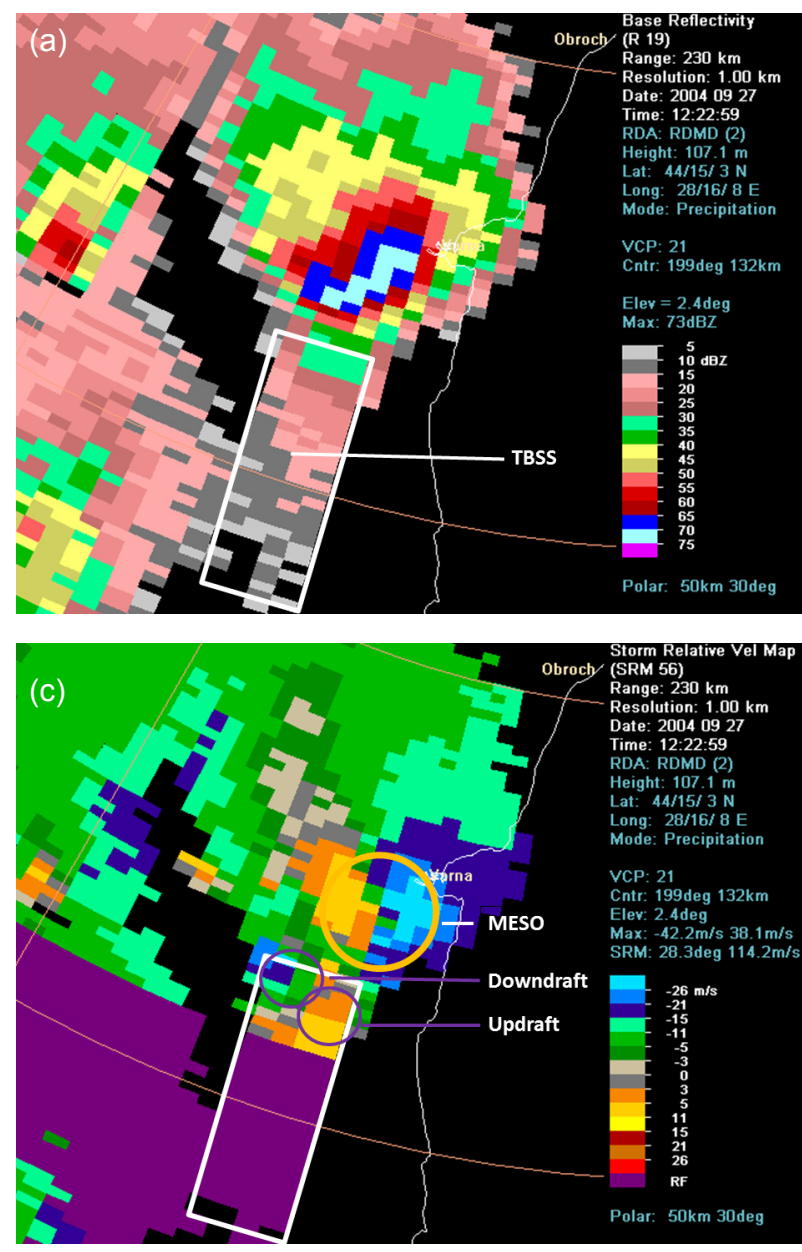

rotational velocity of $17 \mathrm{~m} \mathrm{~s}^{-1}$, cyclonic wind shear of $0.004 \mathrm{~s}^{-1}$ and a diameter of $8 \mathrm{~km}$. This rotational velocity and shear are the most intense in the lifetime of the mesocylone.

In summary, in the region of the TBSS artifact we can have negative values associated with the downdraft region and positive values associated with the updraft in the overhang region (Fig. 15). The storm that affected Varna displayed the TBSS artifact on the S-band radar at Medgidia one hour before the hail fell on the ground.

\subsection{TBSS and the mesocyclone detection algorithm}

The apparent location of the positive or negative velocities inside the TBSS due to hail stones can overlap with the actual locations where motions within the storm are sensed, i.e. the rotation of the updraft. The possible effects can be: (1) enhancement of the inward component of the mesocyclone in the case with negative velocities of the spike; (2) enhancement of

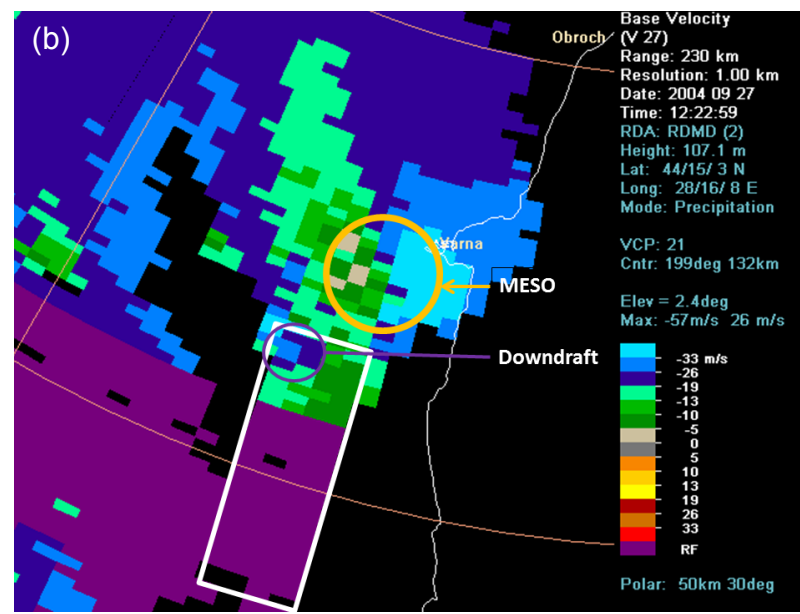

Fig. 13. Base reflectivity (a), base velocity (b) and relative velocity (c) at $2.4^{\circ}$ and 1222 UTC for June 27, 2004 from the WSR-98D radar at Medgidia. The white rectangle indicates the position of the TBSS. the outward component of the mesocyclone if the spike has positive velocities; (3) decrease of either inward or outward true velocity component inside the mesocyclone. These situations are challenging to operational forecasters as they produce false alarms. The first case observed in Romania was presented by Stan-Sion and Antonescu (2006b). Similar cases were reported in different places (Smallcomb, 2006). In order to exemplify these operational difficulties we present a case study from June 3, 2006.

\subsubsection{Case study-June 3, 2006}

A severe hailstorm affected some villages in the central part of Romania. It was observed with the radar at system Bobohalma during the afternoon of June 3, 2006 (Stan-Sion and Antonescu, 2006a). The storm was not only a "hail monster", but also a tornadic storm that prompted the forecaster to issue a tornado warning, which is a rare occurrence in Romania. At the fourth tilt $\left(3.4^{\circ}\right)$ the length of the spike was $18 \mathrm{~km}$ 

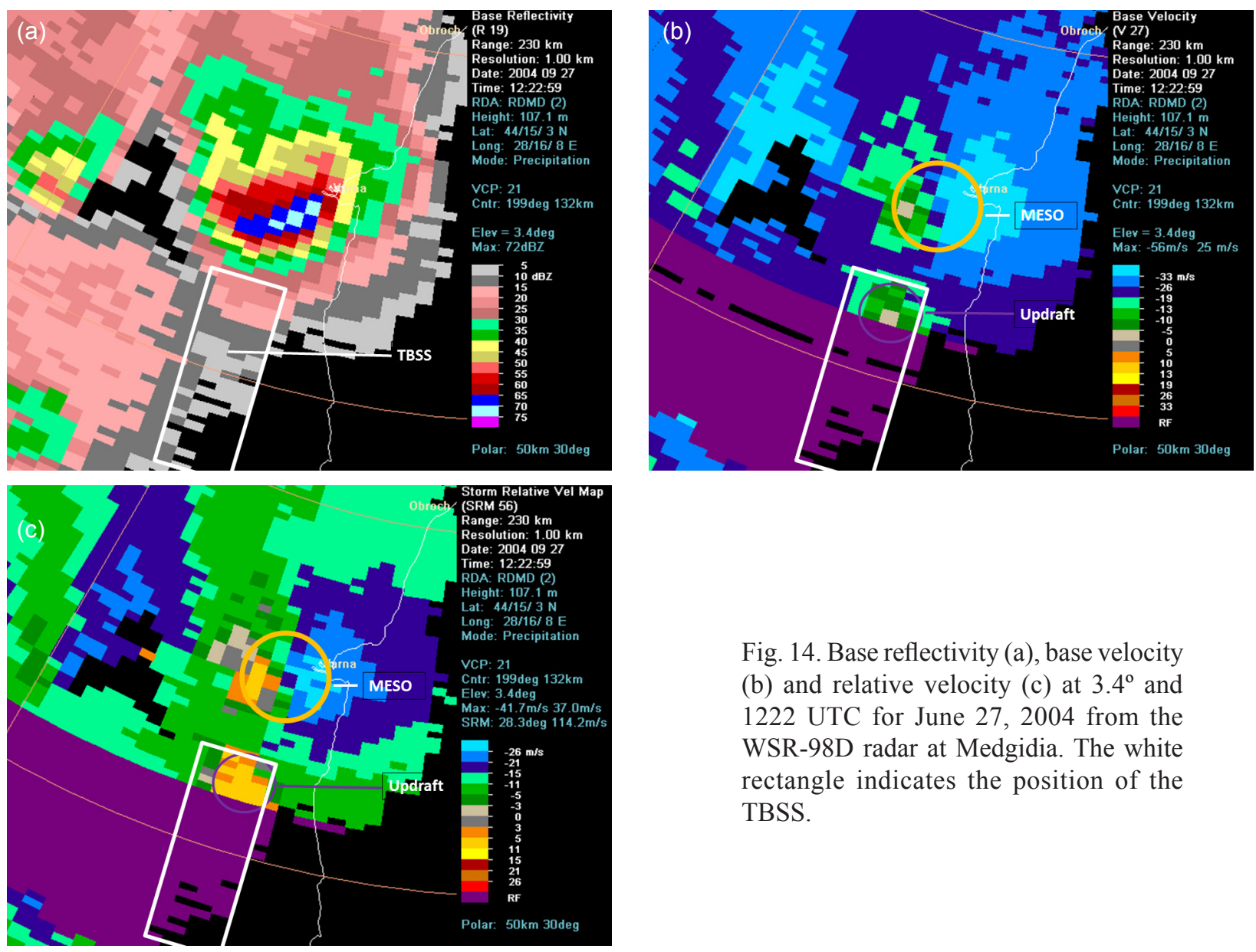

Fig. 14. Base reflectivity (a), base velocity (b) and relative velocity (c) at $3.4^{\circ}$ and 1222 UTC for June 27, 2004 from the WSR-98D radar at Medgidia. The white rectangle indicates the position of the TBSS.
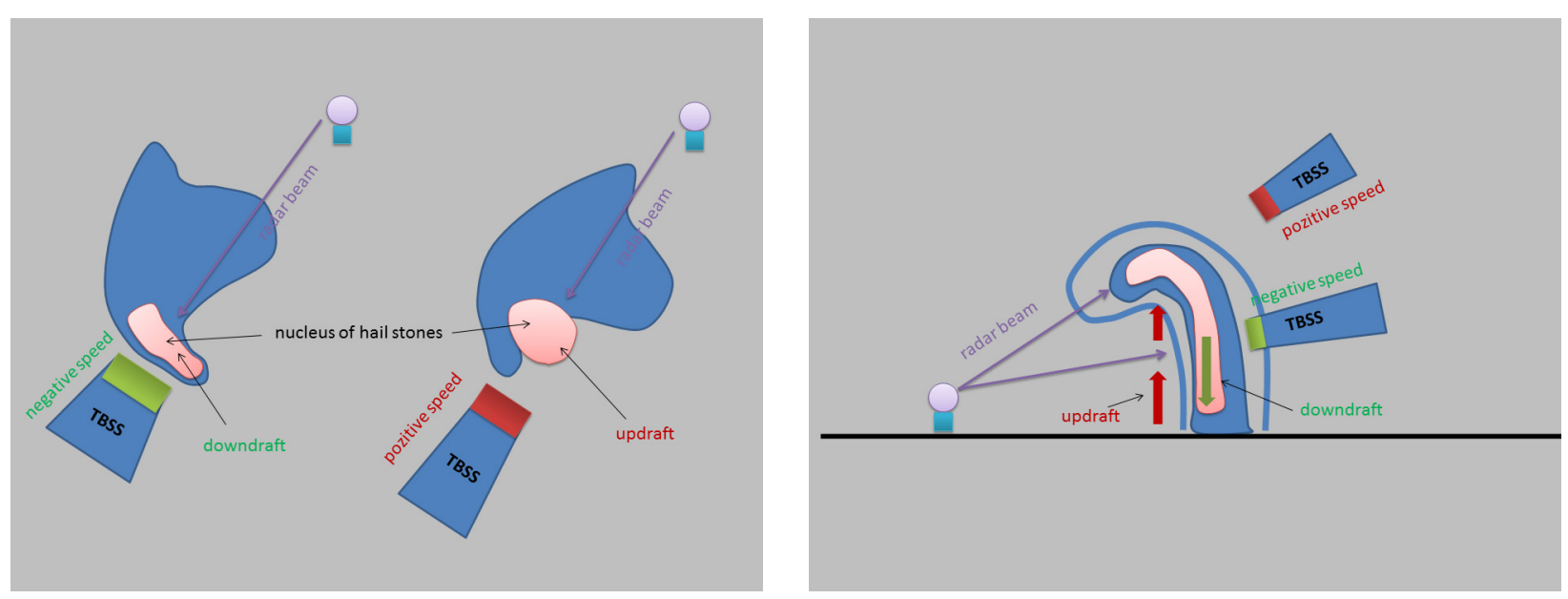

Fig. 15. TBSS artifact. Negative values are associated with the downdraft region and positive values are associated with the updraft in the overhang region: (a) horizontal section, (b) vertical section.

downrange of the highest reflectivity core of $73 \mathrm{dBZ}$, situated at a height of $4.2 \mathrm{~km}$. Along the spike the reflectivity decreased to $5 \mathrm{dBZ}$, which is the threshold for reflectivity display with the WSR-98 principal user processor (PUP). At lower elevations the length of the TBSS spike becomes shorter $\left(10 \mathrm{~km}\right.$ at $\left.0.5^{\circ}\right)$, as expected. It appears that the TBSS perturbed the velocity field producing MESO and TVS structures 


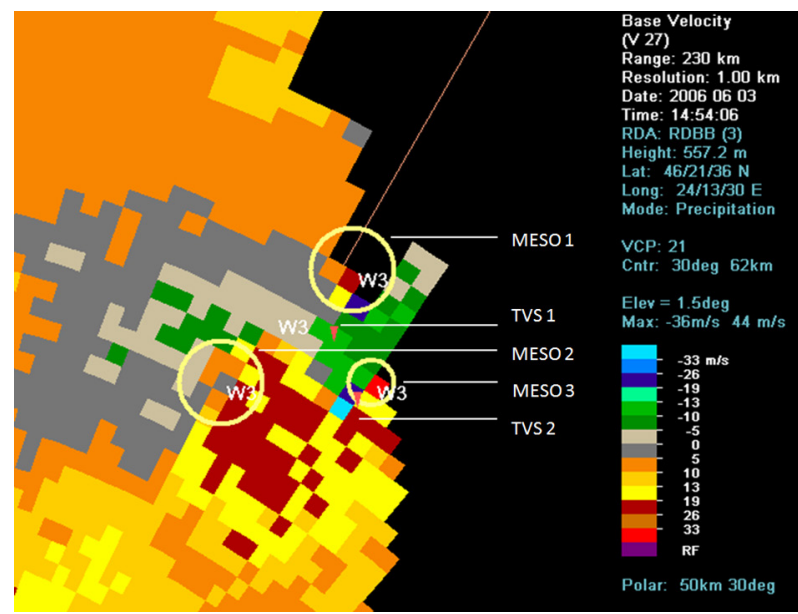

Fig. 16. Base velocity at $1.5^{\circ}$ and 1454 UTC on June 3 , 2006 from WSR-98D at Bobohalma. The yellow circles enclose the MESO and the red triangle represents the TVS as detected by the algorithm.

which were unreal (Figs. 16 and 17), while the mesocyclone detected to the south was consistent with the radial velocities field. The supercell was moving from southwest to northeast producing a "relative to the storm" inflow in low levels oriented from the northeast direction. This inbound component of the low level inflow into the storm can be a reason for

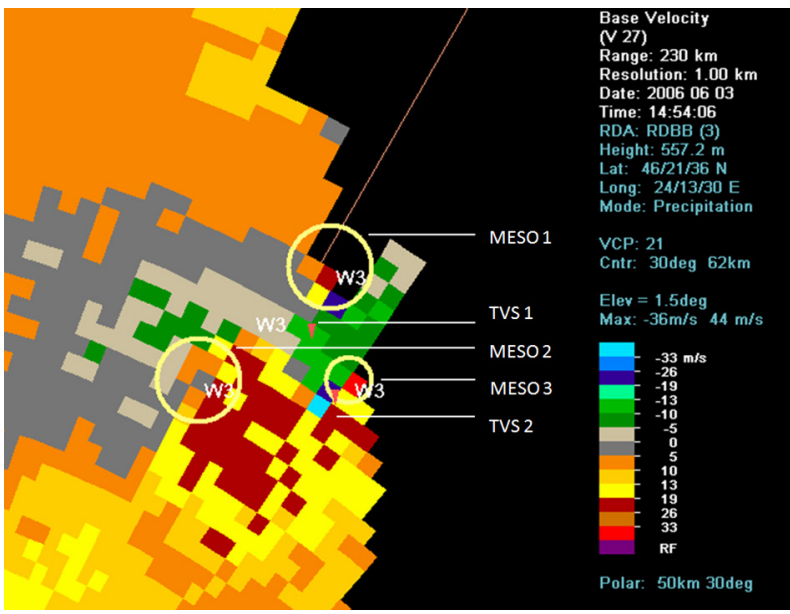

Fig. 17. Base velocity at $2.4^{\circ}$ and 1454 UTC on June 3 , 2006 from WSR-98D at Bobohalma. The yellow circles enclose the MESO and the red triangle represents the TVS as detected by the algorithm.

the enhanced negative velocities in the TBSS spike.

The storm structure shows a very strong supercell with a very well defined mesocyclone, identified by the algorithm (Figs. 18 and 19). However, the second mesocyclone was a false one, caused by the dealiasing failure (Figs. 18 and 19). A closer investigation shows that there are real and relatively strong positive

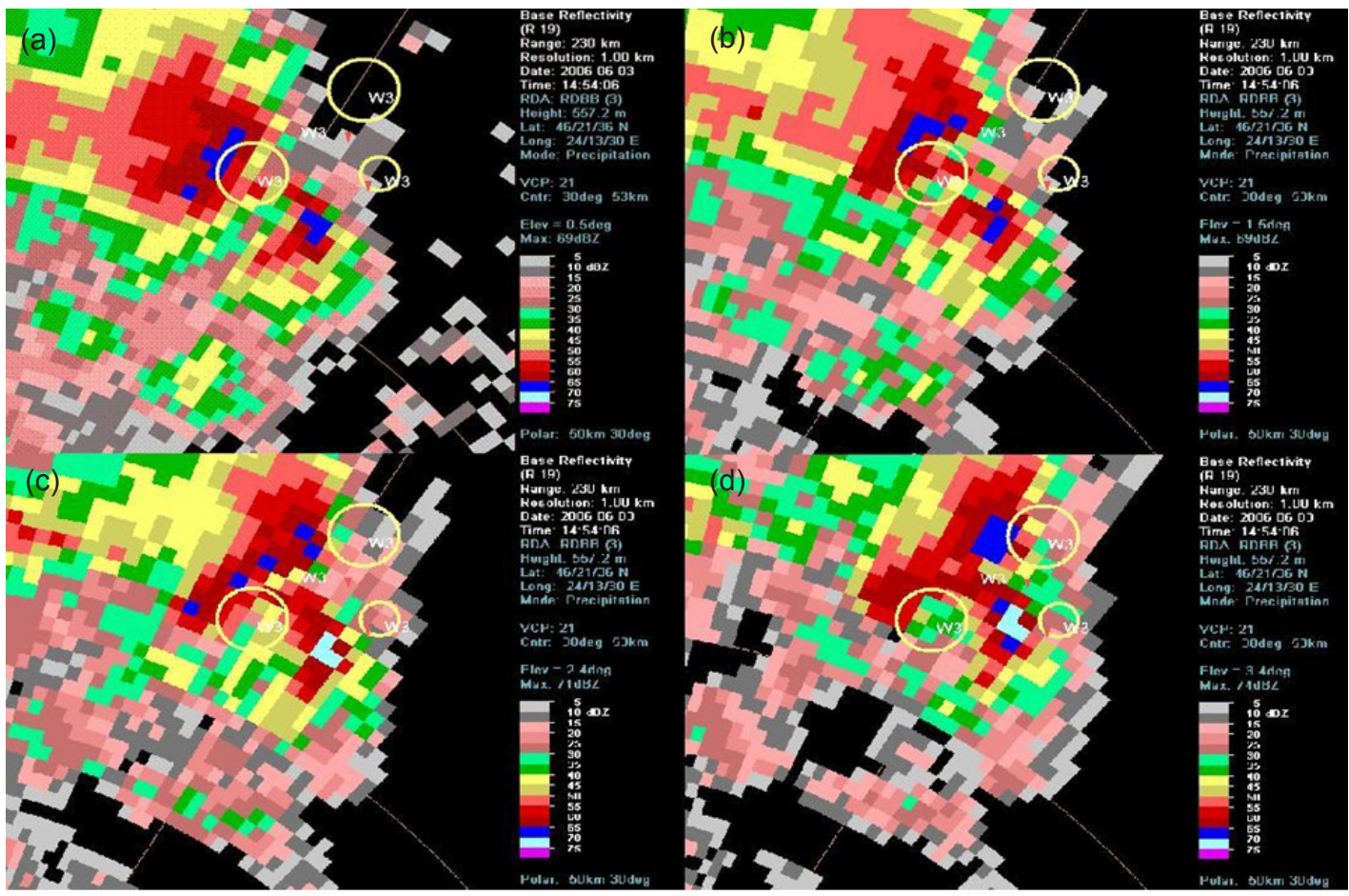

Fig. 18. Base reflectivity at $0.5^{\circ}(\mathrm{a}), 1.5^{\circ}(\mathrm{b}), 2.4^{\circ}(\mathrm{c})$, and $3.4^{\circ}(\mathrm{d})$ at $1454 \mathrm{UTC}$ on June 3,2006 , obtained from the WSR-98D radar at Bobohalma. MESO and TVS as detected by the algorithm. 


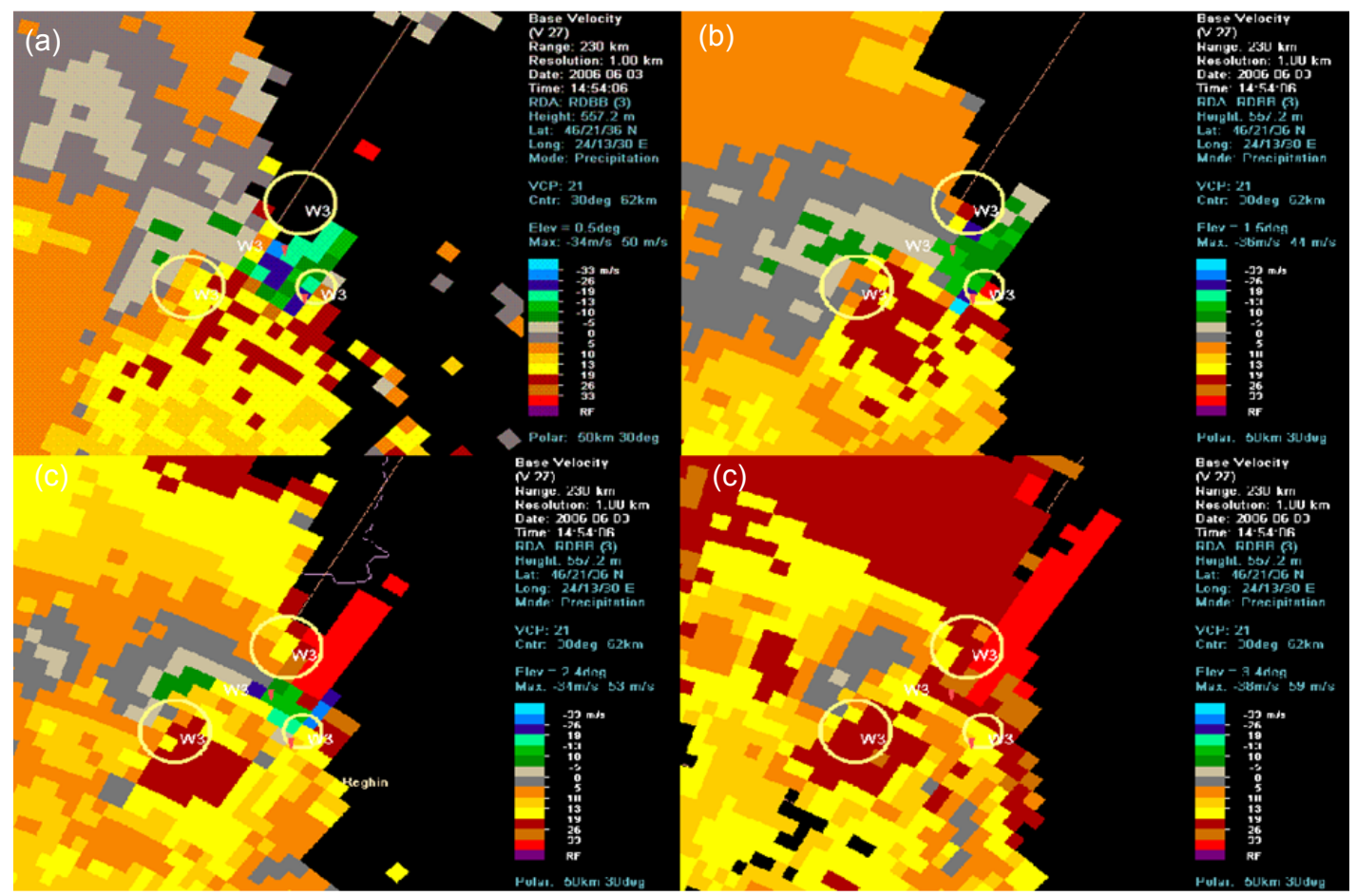

Fig. 19. Base velocity at 0.50 (a), 1.5 (b), 2.40 (c), and 3.40 (d) at 1454 UTC on June 3, 2006, obtained from the WSR-98D radar at Bobohalma. MESO and TVS as detected by the algorithm.

velocities that lead up to the beginning of the TBSS where sharply negative velocities begin. This very strong false convergence leads to a dealiasing failure. This strong shift may be produced by the high downward speeds of the hail stones. We observed that the

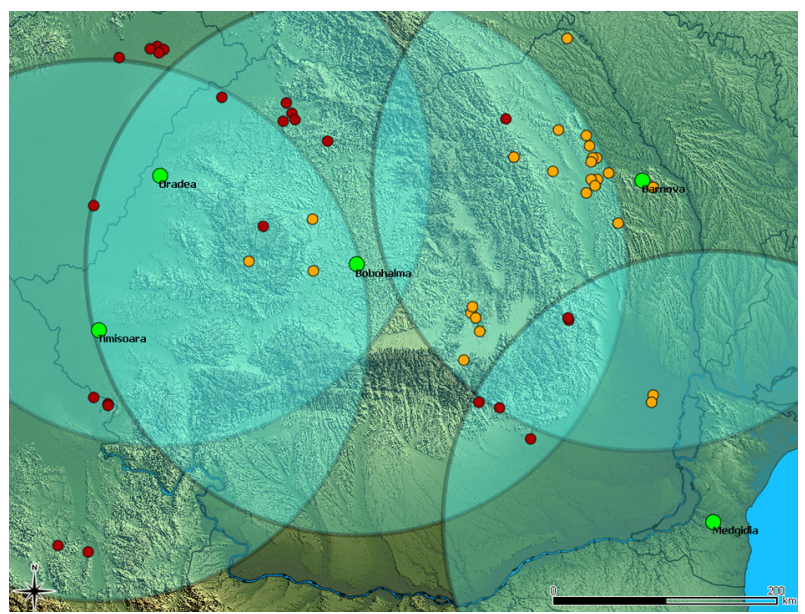

Fig. 20. Coverage domain of the S-band radar units (10 $\mathrm{cm}$ ) across Romania. Green dots represent radar locations and transparent circles represent the coverage domains of the radar units. Orange is for localities where the cell yielding hail had a TBSS and red for localities where the cell did not have a TBSS.
TBSS disturbs the velocity continuity and thus the contamination of the velocity field can be responsible for the failure of the MESO and TVS algorithms. The presence of hail can produce different patterns on reflectivity or velocity.

\section{TBSS spatial distribution and frequency}

The Romanian experience with an S-band network, acquired in the last four years, confirms that the TBSS artifact is associated with hail reports, has the same characteristics as those previously reported and does have an important operational value (Donavon and Jungbluth, 2004).

Fifty seven cases with hail were analyzed, as reported in 57 localities from Romania, Serbia, Bulgaria and the Republic of Moldova over the May-September 2009 interval:

- 26 of the cases, i.e. $46 \%$ of the total number of analyzed cases, had a TBSS associated with the convective cell that produced hail (the TBSS occurred at least once during the cell's evolution - one and the same cell being capable of travelling over more localities);

- 31 of the cases (i.e. 54\%) did not have a TBSS associated with the cell that produced the hail, or 


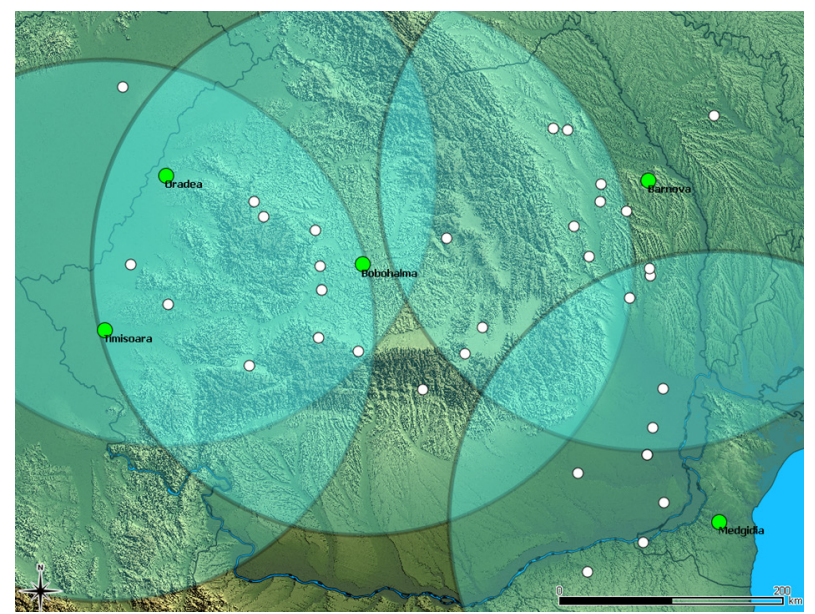

Fig. 21. Coverage domain of the S-band radar units (10 $\mathrm{cm}$ ) across Romania. Green dots represent radar locations and transparent circles represent the coverage domains of the radar units. White is for the points where TBSS were detected.

the TBSS could be masked by the reflectivity field of the neighboring cells;

- TBSS identification was performed in the base reflectivity and velocity fields, where the condition was for the TBSS to occur in at least one elevation. The analysis was performed with the S-band radar units $(10 \mathrm{~cm})$ from Medgidia, Iasi, Bobohalma, Oradea and Timisoara, where the PUP application used by the forecaster displays only reflectivities higher than $5 \mathrm{dBZ}$. The TBSS is likely to display values smaller than $5 \mathrm{dBZ}$ too (Smalcomb, 2006), but these could not be observed due to a reflectivity threshold at $5 \mathrm{dBZ}$.

The abovementioned coverage domain and location of the S-band radar units are rendered in Figures 20 and 21, where the green, transparent circles represent the coverage domain and the green dots the location of the radar units. The area of the C-band radar units $(5 \mathrm{~cm})$ was disregarded in the analysis.

Localities are represented on the map in Figure 20, where hail events were reported in the ESWDB base. The red color represents the localities where the hail event was not associated with the presence of TBSS and the orange the localities where hail was associated with the presence of TBSS.

We found a better correlation between the reported hail and TBSS identification in the northeastern part of the country (Fig. 20), where the TBSS was present in supercellular storms with a longer life time, some of the cells travelling over more than one locality. In the other areas, the correlation might have been affected by the position of the storm within the convective system. Regarding the localities beyond the Romanian borders, situated too far from the radar, the radar beam only passed through the upper part of the storm, whereas hail could have been rallied by downdraft flows, at elevations lower than that of the beam. Figure 21 renders all the cases where the TBSS was detected, irrespective of whether hail on the ground was reported or not. Those cases were distributed as follows: 9 TBSS cases, Megidia (MD) radar; 9 TBSS cases, Barnova (IS) radar; 5 TBSS cases, Oradea (OD) radar; 10 TBSS cases, Bobohalma $(\mathrm{BB})$ radar.

For each of the cases mentioned in the Severe Weather Database (http://www.essl.org/cgi-bin/eswd/ eswd.cgi) archive, an analysis of TBSS occurrence was performed (Fig. 21). The analysis tracked the TBSS occurrence along the trajectory of the storm that yielded hail on the ground. In all the correlated cases, the TBSS occurred prior to the hail falling or right at that moment.

The performed analysis highlights that TBSS is associated with some of the hail-yielding cells (in the above analysis, identification was made in the archive of the cases with hail reports, then the radar field was analyzed). Those cells displaying TBSS in the course of their evolution were generally sparse cells of high reflectivities and mesocyclones (supercells).

\section{Conclusions}

A first conclusion is that TBSS occurrences (Fig. 21) are not rare in Romania. The second conclusion, highlighted by the performed analysis, is that the TBSS is associated with some of the hail-yielding cells (Fig. 20) and these cells were generally sparse cells of high reflectivities and mesocyclones (supercells). This second conclusion leads us to think on "conceptual models for severe hail" in the same way we were deriving conceptual models for mesocyclonic storms (Stan-Sion and Antonescu, 2006a). The last conclusion is that, exactly in the most difficult situations, like tracking severe convection, the forecaster should not blindly trust the algorithms.

The TBSS signature is a very important warning tool, although it cannot give an anticipation of more than 30 minutes, since it is detected at high levels in the storm; however, the hail spike can affect the 
radial velocities and produce disruptions in the radial velocity field that can generate unreal mesocyclonic and tornadic vortex patterns, and these may be artificially identified by the algorithm. In this case severe weather (both large hail and tornado) was reported at the ground and the warning was correctly issued, despite the "interference" between the TBSS and the radial velocities analyzed by the MESO and TVS algorithms. The problem is most critical when a scanned low-level mesocyclone is immediately downrange of a hail core, which is not an unusual situation for a supercell storm. Subjective verification of the characteristic pattern of the supercell is extremely important in order to "validate" the output of the severe weather detection algorithms.

\section{References}

Carbunaru D. V., S. Burcea, M. Sasu, B. Antonescu and A. Bell, 2010. Three body scatter signature climatology in Romania. Proceedings of the Sixth European Conference on radar in Meteorology and Hydrology. ERAD, Sibiu, Romania.

Donavon R. A. and K. Jungbluth, 2004. Establishing a comprehensive severe warning criteria for large hail across the Upper Midwest and Central Plains. Severe Storm and Doppler Radar Conference. National Weather Association. West Des Moines, IA.

Lemon, L. R., 1978. On the use of storm structure for hail identification. Preprints, 18th Conf. on Radar Meteorology, Atlanta, GA, Amer. Meteor.Soc., 203-206.

Lemon L. R., 1998. The radar "three-body scatter spike": An operational large-hail signature. Weather Forecast. 13, 327-340.

Lindley T. T. and L. R. Lemon, 2007. Preliminary observations of weak three-body scatter spikes associated with low-end severe hail. Electronic J. Severe Storms Meteor. 2, 1-15.
Mitchell E., S. De Wayne, V. Vasiloff, G. J. Stumpf, A. Witt, M. D. Eilts, J. T. Johnson, K. W. Thomas, 1998. The National Severe Storms Laboratory tornado detection algorithm. Weather Forecas. 13, 352-366.

Smallcomb C., 2006. Hail spike impacts on Doppler radial velocity data during several recent lower Ohio Valley convective events. Preprints of the 23rd Conference on Severe Local Storms. St. Louis, MO.

Stan-Sion A. and B. Antonescu, 2006a. Radar three body scatter signature (TBSS) observed with Doppler radar network in Romania - operational aspects. Preprints of the Fourth European Conference on Radar in Meteorology and Hydrology. Barcelona, Spain.

Stan-Sion A. and B. Antonescu, 2006b. Mesocyclones in Romania - characteristics and environments. Preprints of the 23rd Conference on Severe Local Storms. St. Louis, MO.

Stan-Sion A., B. Antonescu and D. V. Carbunaru, 2007. Three body scatter signature producing uncertainties on Doppler radial velocity structures. Proceedings of the 33rd AustralianInternational Meteorology Society Conference on Radar Meteorology. AMS, Cairns, Queensland, Australia.

Stumpf G. J., A. Witt, E. D. Mitchell, P. L. Spencer, J. T. Johnson, M. D. Eilts, K. W. Thomas and D. W. Burgess, 1998. The National Severe Storms Laboratory mesocyclone detection algorithm for the WSR-88D. Weather Forecast. 13, 304-326.

Wilson J. B. and D. Reum, 1988. The flare echo: reflectivity and velocity signature. J. Atmos. Ocean. Tec. 5, 197-205.

Zrnic D. S., 1987. Three-body scattering produces precipitation signature of special diagnostic value. Radio Sci. 22, 76-86.

Zrnic D. S., G. Zhang, V. Melnikov and J. Andric, 2010. Three-body scattering and hail size. J. Appl. Meteor. Climatol. 49, 687-700. 